Advances in Dynamical Systems and Applications.

ISSN 0973-5321, Volume 16, Number 1, (2021) pp. 317-333

(C) Research India Publications

https://dx.doi.org/10.37622/ADSA/16.1.2021.317-333

\title{
The Multiple Source Control Method for Functional- Structure Modernization of Reconfigurable Infocommunication Environments
}

\author{
Loginov I.V. ${ }^{1}$, Kuzichkin O.R. ${ }^{2}$, Eremenko V.T. ${ }^{1}$, Vasilyev G.S. ${ }^{2}$, \\ Eremenko A.V.1, Surzhik D.I. ${ }^{2}$ \\ ${ }^{1}$ Orel state University named after I. S. Turgenev, Orel, 302026, Russia. \\ ${ }^{2}$ Belgorod State University, Belgorod, 308015, Russia.
}

\begin{abstract}
Infocommunication environments of extended agro-industrial enterprises in the context of precision farming strategy provide various types of information and telecommunication services. External factors change leads to reconfiguring such system to new operational requirements. There are different types of resources needed to maintain process of system modernization. At the same time, it is a typical situation of many resources vendors with different characteristics. The problem of multiple source control for reconfiguration of infocommunication environments under uncertainty is considered in the article. The proposed algorithm allows to evaluate the quality of modernization plans and source control according to the value of the potential effect and characteristics of sources. The basic foundations of the algorithm are sources flow monitoring and modernized first - most timeliness (FMT) method for alternative selection and resource flow control. To estimate the effect of the alternatives, the special cost function is used. It is expected that the proposed source control method will help to improve the IT systems resource provision and increase their suitability in the case of uncertainty.
\end{abstract}

Keywords: Infocommunication environment, non-stationarity, reconfiguration, source control, resource flow, decision-making. 


\section{INTRODUCTION}

Infocommunication environments of the modern agro-industrial enterprises are complex technical systems. They provide various types of information and telecommunication services to to improve the technical and management processes in agro-industrial complex. There are many different components included in the infocommunication environment. Modernization of the reconfigurable infocommunication environment is implemented by multiple modernization activities for IT components. A significant number of modernization projects improve the efficiency (suitability) of the system.

There are different type of resources needed to maintain process of system modernization, such as human, money, time, programs and electronic components, telecommunications services. For extended agro-industrial enterprises, it is typical situation of many resources vendors. Every information resources have their own characteristics of flow intensity, type of resources, working time and so on. A large number of alternative modernized system components and the limited resources allocated to system development determine the need of multiple source control. This problem currently is being solved by some optimization methods. But the conditions of source characteristics uncertainty and increase the modernization time don't fully take into account. Generally this situation decrease the system's suitability and resources provision. Thus, the problem of developing a method of multiple source control for functional-structure modernization of reconfigurable infocommunication environments under uncertainty of the sources characteristics and IT modernization requests flow is urgent now.

\section{THE REVIEW OF APPROACHES TO MULTIPLE SOURCE CONTROL METHOD INFOCOMMUNICATION ENVIRONMENTS}

The task for the development of infocommunication environment due to changes in external and internal factors determines the need for an effective resources flow. This situation specify control mechanism for sources of IT resources. The problem of multiple source control for reconfigurable infocommunication environments under uncertainty of the sources characteristics are investigated by many authors. The main methods implement the definition of the order, methods and techniques of development management for management systems [1-4].

Controlling of external sources of components and materials (including IT components) by planning methods are currently being actively developed primarily for the head executors of complex technical systems in the field of mechanical engineering, as determined by the multitude of components supplied by hundreds and thousands of vendors (in this case, products, including IT components, must be delivered of proper quality on a "just-in-time" basis) [5]. The expansion of the practice of providing 
external IT resources has led to the need to adapt the existing mathematical apparatus for selecting and evaluating third-party components to the factors and conditions of the infocommunication environments.

The factors that determine the development of the supplier and the risks of its choice have a significant impact on the provision of IT system throughout their life cycle. The main reasons for the need to evaluate suppliers are: reducing risk, increasing added value and establishing close relations between producers and consumers. A number of factors aggravate the vendor selection and management difficulties for IT infrastructure. There are several characteristics of infocommunication environments that make sources control problem more complex: unique features of the IT components modernization projects, heterogeneity in source quality and nonverifiable result, unprecedented rate of technological change.

The problem of selecting suppliers refers to problems of multi-criteria decision making in the presence of several antagonistic factors, and their evaluation is related to problems of multi-criteria assessment. The basic control methods used to manage source of IT components are reduced to: linear weight models, categorical models, weighted point models, full cost of ownership models, neural networks, the main component method, multivariate utility theory $[5,6]$. To improve evaluation accuracy, integration of various methods of analysis is widely used, in particular, [7] offers integration of interpretive structural modeling (interpretive structural modeling) and analytical networks, Decision making trial and evaluation laboratory (DEMATEL) technique [8,9]. Further development of evaluation methods under uncertainty is associated with analysis of hierarchies and its extensions taking into account the Fuzzy extended analytical hierarchical process (AHP) [10,11] or hybrid approaches to evaluation [6].

Depending on the situations, many approaches to solving the problem of source management by distinguished methods, due to various restrictions. The consumeroriented model discussed in [12] requires more attention to the needs of end users when evaluating a vendor. The automation-oriented model discussed in [13] offers the minimization of the integrated cost of support with limitations on quality, service and time. Context-sensitive model [14] involves experience in supplier evaluation and applies an ontological approach to the selection problem. The template approach to the presentation of the supplier assessment problem [15] involves its solution through the use of agreement patterns. A trustworthy approach to selecting a supplier requires considerable attention to the degree of confidence in the supplier in the evaluation process.

Most of the approaches use the hierarchy analysis method by evaluating IT components sources $[5,16,17]$. It involves the development of multilevel hierarchies, according to which various alternatives are evaluated. For example, in [17], six hierarchy levels are 
identified, with two indicators at the strategic evaluation level: resources and quality, which at the criteria level are deployed into capital and operating costs, technical and operational quality, and supplier quality. In general, the number of evaluation indicators considered is very large (most studies consider the $15 \ldots 25$ of private indicators). According to most studies, the importance of indicators is ranked in the following order: price, accuracy, quality, supplier capabilities, and technical capabilities [18].

The Decision making trial and evaluation laboratory (DEMATEL) method is widely used in order to detect the cause and effect interaction among main criteria in IT components sources control. The source which is closest to the ideal solution and farthest from the negative ideal solution is selected as the best source. DEMATEL technique is considered as an effective method for the identification of cause-effect chain components of complex infocommunication environments as a kind of a complex system [8]. There are five kinds of DEMATEL technique are used for supply chains management. They are classical DEMATEL, fuzzy DEMATEL, grey DEMATEL, analytical network process DEMATEL, and unclassified DEMATEL technique. This technique can confirm interdependence among factors and create a map to viewed relationships within them and can be used for investigating and solving sources management problems. The problems of vendor selection in Global Software Development with integrated method of the fuzzy DEMATEL approach and the Technique for Order Performance by Similarity to Ideal Solution (TOPSIS) approach are suggested in [19]. A two-stage vendor selection process in IT outsourcing are viewed in [20]. In the first stage, the management system engages sources for pilot projects and estimates their characteristics. For the second stage the only high-quality source are used for resources receiving. A combination of grey theory and DEMATEL techniques is used in [9] to find out cause-effect relationships among the enablers of electronic supply chain risk mitigation. This approach can solve some particular problems in multiple source management. Appling the DEMATEL method to explore the core effect in the infocommunication design companies are investigated in [21]. In [22] supplier selection problem for extended enterprise by integrated DEMATEL and TOPSIS methodology is solved. It is used to select the source providing customer through determined criteria. The weights of criteria are calculated using Analytic Network Process approach. The final selection are made by modified TOPSIS.

Increasing the amount of IT resources from external sources used in the reconfigurable infocommunication environment development requires their more accurate control. This makes it necessary to develop a method of multiple source control under uncertainty of the sources characteristics.

\section{RESEARCH PROBLEM}

Modernization of an infocommunication environment of extended enterprises is 
implemented by improving its individual components with the model offered in [23]. The requests of infocommunication component (IT) $S_{i}$ modernization enter to the management system $M S$. The total resources for maintenance and modernization of the system functioning are formed by summing the specific resource consumption by the IT components. Management system goal is to develop controlled infocommunication environment with the aim to maximize criterial function. Such components are characterized by many alternatives for modernization, the effect of which depends on the applied organizational and technical solutions with different resources requirements.

All resources entered to the resource pool from many various sources (vendors) of IT components $V_{j}$ are shown in the Figure 1. Every information source $V_{j}$ has its own characteristics of flow intensity, type of resources, working time, control mechanism and so on. The situation of uncertainty in resources flow characteristics therefore to use special methods of resource allocation. In the reconfigurable systems such problem increases as a result of the requests of IT components (IT) modernization flow uncertainty.

Mathematically a problem may be described by the following objectives:

1) the infocommunication environment $S$ includes several IT components $S_{i}$ that can be upgraded by the management system $M S:\left\{S_{i}\right\}, i=(1, I)$.

2) requests of IT component modernization $S_{i}$ enter the management system with uncertainty flow $\lambda_{\text {ITreq }}(t)$.

3) management system $M S$ is developing infocommunication environment $S$ by basic control actions $U=\left\{u_{\text {add }}, u_{\text {del }}, u_{\text {mod }}\right\}$ :

$-u_{\text {add }}$, creating (adding) new IT component to the environment;

$-u_{\text {mod }}$, modernization of existing IT component;

$-u_{d e l}$, rejecting (decommissioning) of existing IT component.

The control action is generated in according to maximum of a criterial function

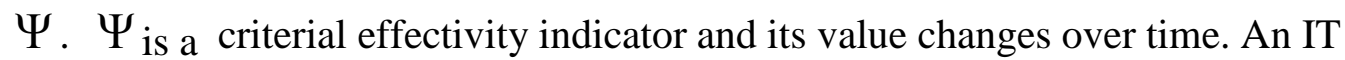
service is created on the basis of the received request, if required resources are available. Requests that can't be servicing due to lack of resources are rejected.

4) for the operation of the system $S$, resources $R_{S}$ are used: $R_{S}=\sum_{i=0}^{I} R_{i}$; to modernize the system $S$, resources $R_{M}$ can be used: $R_{M}=\sum_{i=0}^{I} r_{i}$, where $r_{i}-$ 
resources for the modernization of the IT component $S_{i}$ during the planning period.

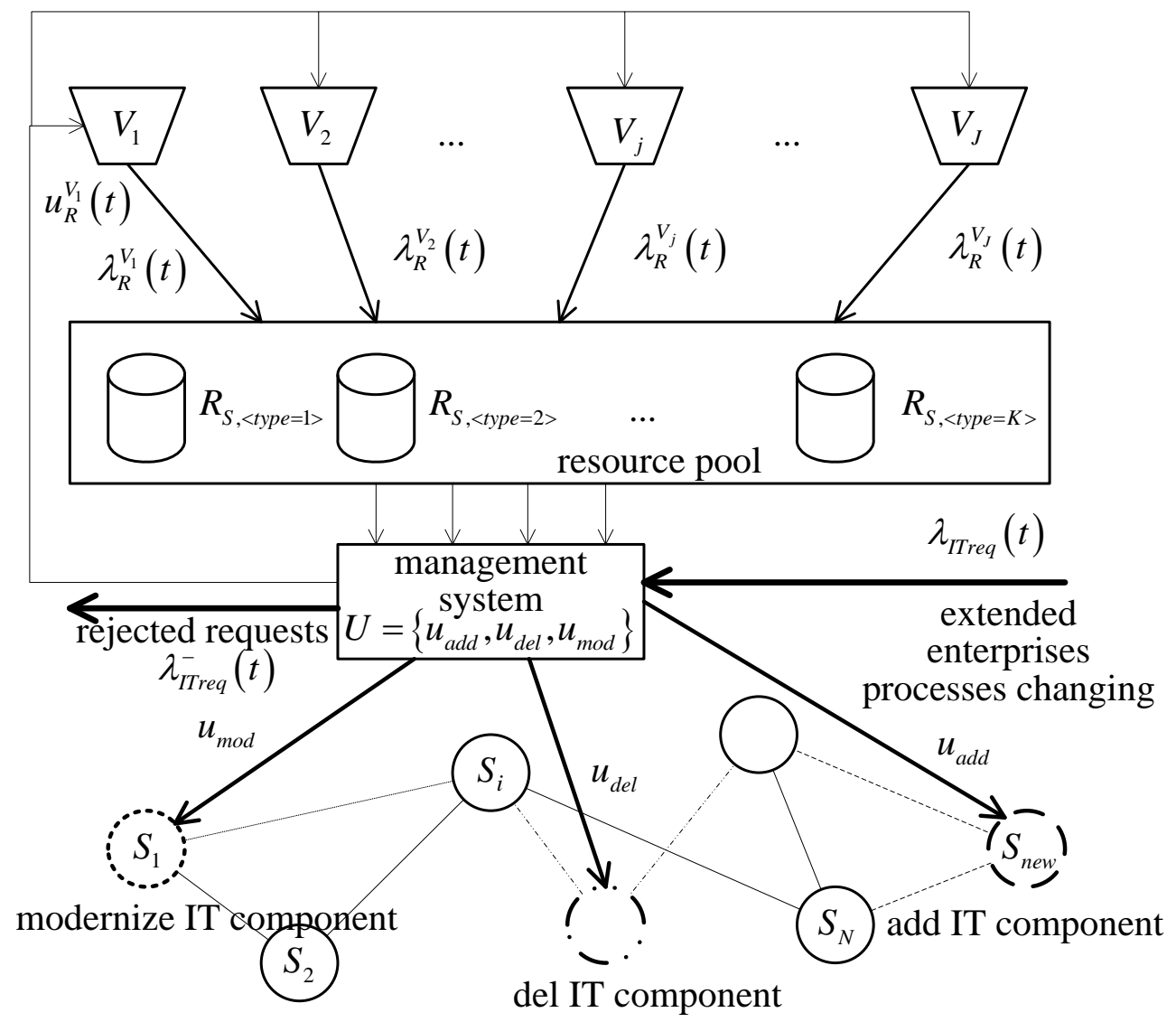

infocommunication environment $S$

Figure 1. Multiple sources allocation in the modernization of reconfigurable infocommunication environments of extended enterprise.

5) new resources are entered to the resources pool from multiple sources (internal or external vendors) $V_{j}$. The characteristics of resources flow $\lambda_{R}^{V_{J}}(t)$ are uncertain.

6) to provide IT resources from sources management system, controls actions $u_{R}^{V_{1}}(t)$ are realized. This control includes: requested resources intensity by types of resource, planned time and resources cost.

The goal of article is to create a new method $A$ of multiple sources resource allocation in the processes of reconfigurable infocommunication environments modernization. 


\section{CRITERIA FUNCTION FOR DECISION-MAKING}

Management system $M S$ develops the infocommunication environment $S$ by basic control actions to IT components according to requests of IT component's $S_{i}$ modernization $\operatorname{ITreq}_{k}$.

All requests $I$ Treq $q_{k}$ fall into the queue ITreq. The Management system MS makes a decision on each request $U$ during each management cycle:

- "process" - tasks are performed and IT services are created or upgraded in the IT department with intensity $\lambda_{\text {ITreq }}^{<\text {process }>}(t)$;

- "reject" - tasks for the creation and modernization of IT services, which were denied execution, denote through, are discarded with intensity $\lambda_{\text {ITreq }}^{<\text {reject }}(t)$;

- "leave in queue", tasks are leaved in the queue for next management cycle with intensity $\lambda_{\text {ITreq }}^{<\text {que }>}(t)$.

The control action is generated in according to criterial function $\Psi$ maximum. The criterion and rules $\Psi$ for selecting requisitions according to their characteristics and primarily the value for the organization's processes can be described in the form of a cost function [24]. As part of the work, a variant of this function was obtained for the IT department to select requests with 4 priorities for creating information services in the organization.

Based on the hierarchies analysis method from the multicriterial utility theory, criterial function was developed for request of each priority. These criteria were proposed to experts for their assessment and summarized. Based on the estimates received, a cost function was proposed.

All requests (from the queue) are considered at each management cycle [25]. Each decision stage (creating an IT service, refusing to create an IT service, queuing an IT service) is considered separately. The cost function is considered for all three actions for each requisition (four levels of importance) and for the size of the queue:

$$
\Psi=\sum_{k=1}^{K} C_{k, p r i o r}^{a c t}\left(t_{k}\right)-C_{K},
$$

where $C_{k, \text { prior }}^{a c t}\left(t_{k}\right)$ - cost of one from control action \{"process", "reject", "leave in queue" $\}$ for $k$ IT component request $I$ Treq $q_{k}$ with priority prior in moment $t_{k} ; C_{K}$ - negative effect of queue size. 
$C_{k, \text { prior }}^{<\text {reject }}\left(t_{k}\right)$ and $C_{k, \text { prior }}^{<\text {leave }}\left(t_{k}\right)$ are constant negative effect of such decision and there value depend from priority of IT request.

The function of $C_{k, p r i o r}^{<\text {procss }}\left(t_{k}\right)$ may be constrained with the assumption that the measure the benefits of an IT request procession is to use a utility measure that mean the overall value to the extended enterprise of the IT environments improvements being implemented. In the article the positive effect was account for 4 priorities of process based on practical estimation of IT components usefulness:

$$
C_{k, \text { prior }}^{<\text {process }}\left(t_{k}\right)=\int_{t_{k}+\tau}^{t_{k}+\tau+T} \xi_{k}(t),
$$

where $\xi_{k, p r i o r}(t)$ - utility function that showcase current positive effect from modernized IT component, $\tau$ - modernization time, $T$-useful functioning time of an IT component.

\section{MULTIPLE SOURCE CONTROL METHOD IN INFOCOMMUNICATION ENVIRONMENT}

The proposed source control method based on optimal resource allocation with maximizing of current total positive effect of IT project execution. This method based on planning mechanism is named FMT, that means "first - most timeliness (request for executing)".

Main provisions of the FMT planning mechanism intend to select most timely IT project from queue for reconfiguration purpose. The main idea is to generate on each decision the set of reconfiguration plan $P=\left\{P_{i}\right\}: P=\langle G, T\rangle$, where $G$ is the order of modernization of components and $T$ is the planned moments of the modernization start time for all request in queue. For every plan there are estimating current total positive effect $E(P)=\sum_{i=1}^{N} E\left(a_{i}\right)$. By stochastic optimization we find optimal plan $E(P) \rightarrow \max$ with resource constrains $\sum_{i=1}^{N} R\left(a_{i}\right) \leq R^{V}$. This method works with limited resources: $R^{V}=$ const .

In the work the situation of non-stationary resources flow from multiple sources with different characteristics are investigated. To solve this problem, the modernized algorithm was proposed (Figure 2). 
The input data of the algorithm:

- the infocommunication environment $S$ with potentially upgraded IT components $S_{i}$, where $I$ - number of components, $I=I(t)$;

- number of sources $J$;

- number of resources type $K$;

- constraints on source controls actions $\tilde{u}_{R}^{V}(t)$.

The output data of the algorithm:

- IT component $S_{i}$ modernization ITreq $_{k}$ for implementation;

- sources control actions $u_{R}^{V}(t)$.

The multiple source control method in the infocommunication environment (Figure 2) may be divided into several basic stages.

Stage I: In this stage, the external and internal characteristics of infocommunication environment are being monitored, and characteristics of requests $\hat{\lambda}_{\text {ITreq }}(t)$ and sources $\hat{\lambda}_{R}^{V}(t)$ flow are estimated.

Stage II: In this stage, the set of IT requests $A=\left\{a_{i}\right\}$ is formed from queue and requests flow $\lambda_{\text {ITreq }}(t)$. This set of IT requests define all potentially modernized components.

Stage III: In this stage, the basic characteristics of IT request service are calculated. They are: positive effect $c_{i}(t)$, resource requirements $r_{i}(t)$, reconfiguration time (planned duration of time for IT project) $\varphi_{i}(t)$. 


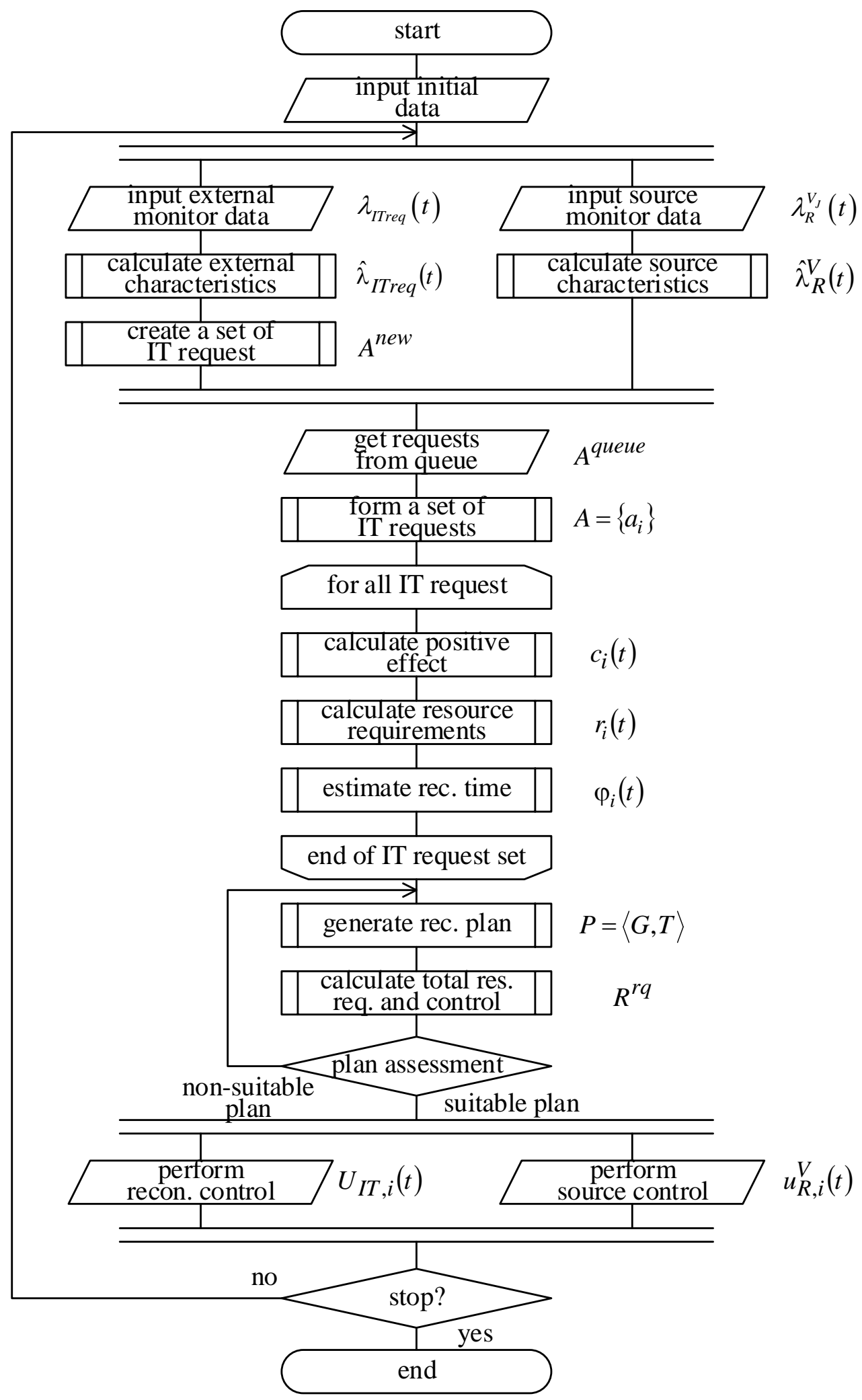

Figure 2. The algorithm of source control during reconfiguration. 
Stage IV: In this stage, the reconfiguration plan set $P=\left\{P_{i}\right\}$ is generated. For each plan, the total resource requirements $R_{\text {ITreq }}(t)$ are calculated and planned source control actions $u_{R}^{V}(t)$ are generated. In this stage the stochastic optimization method are used for generating suitable reconfiguration plan with the criteria function (1).

Stage $V:$ In this stage the control actions are applied:

- $U_{I T, i}(t)$ to perform reconfiguration control by IT request chosen for modernization;

$-u_{R}^{V}(t)$ to control total source flow formation $\lambda_{R}^{V}(t)$ with accordance to positive required resource flow: $\lambda_{R}^{V}(t)-\lambda_{R}^{I T r e q+}(t) \rightarrow \min$.

The proposed algorithm allows to evaluate the quality of modernization sequences and plan source control according to the size of the potential effect and characteristics of sources.

\section{SOURCE CONTROL METHOD: A CASE STUDY}

Source control method proposed in the work are applied for modelled infocommunication system with more then 200 IT and communications services. The IT request flow includes 2 types of requests $\Lambda=\sum_{i=1}^{4} \lambda_{i}=\lambda_{\langle\mathrm{BC}\rangle}+\lambda_{\langle\mathrm{MC}\rangle}$. Resources are under limit. Part of IT requests are not serviced and rejected.

\section{Modelled situation:}

One year of system functioning was modelled. Total resource flow from several sources $\lambda_{R}^{V}(t)$ is twice as small as required resource flow $\lambda_{R}^{I \text { ITreq }}(t): \rho=\lambda_{R}^{I T r e q} / \lambda_{R}^{V} \approx 2$. There are two types of resources taken into account in the experiment: $R_{1}$ and $R_{2}$. At the start of experiment the ratio between types of resource is the same in both resource flows: $\lambda_{R 1}^{\text {ITreq }}(0)=\lambda_{R 2}^{\text {ITreq }}(0), \lambda_{R 1}^{V}(0)=\lambda_{R 2}^{V}(0)$. At one moment $(T=180)$ the IT request flow is changed: $\lambda_{R 1}^{\text {ITreq }}(180) \neq \lambda_{R 2}^{I T r e q}(180)$.

The following alternatives of infocommunication system development methods are compared:

- 〈DP $\rangle$ - dynamic priority, a kind of scheduling algorithm in which the priorities are calculated and changed during the system's functioning; 
- <FMT $>-$ first most timeless scheduling algorithm;

$-<$ FMT + ASC $>$ - first most timeliness and adaptive source control method, the scheduling algorithm in which combines source control and IT request choice mechanism.

Figure 3 shows the histogram of average values of criteria functions for the compared alternatives of selection algorithms: $\bar{C}_{\langle\mathrm{DP}\rangle}, \bar{C}_{\langle\mathrm{FMT}\rangle}$ and $\bar{C}_{\langle\mathrm{FMT}+\mathrm{ASC}\rangle}$. Restrictions on the rejection time from the queue ( $\tau=20$ ) lead to the emergence of a transition mode at the beginning of the experiment, as long as transition sections at the required resource flow change (indicated by hatching).

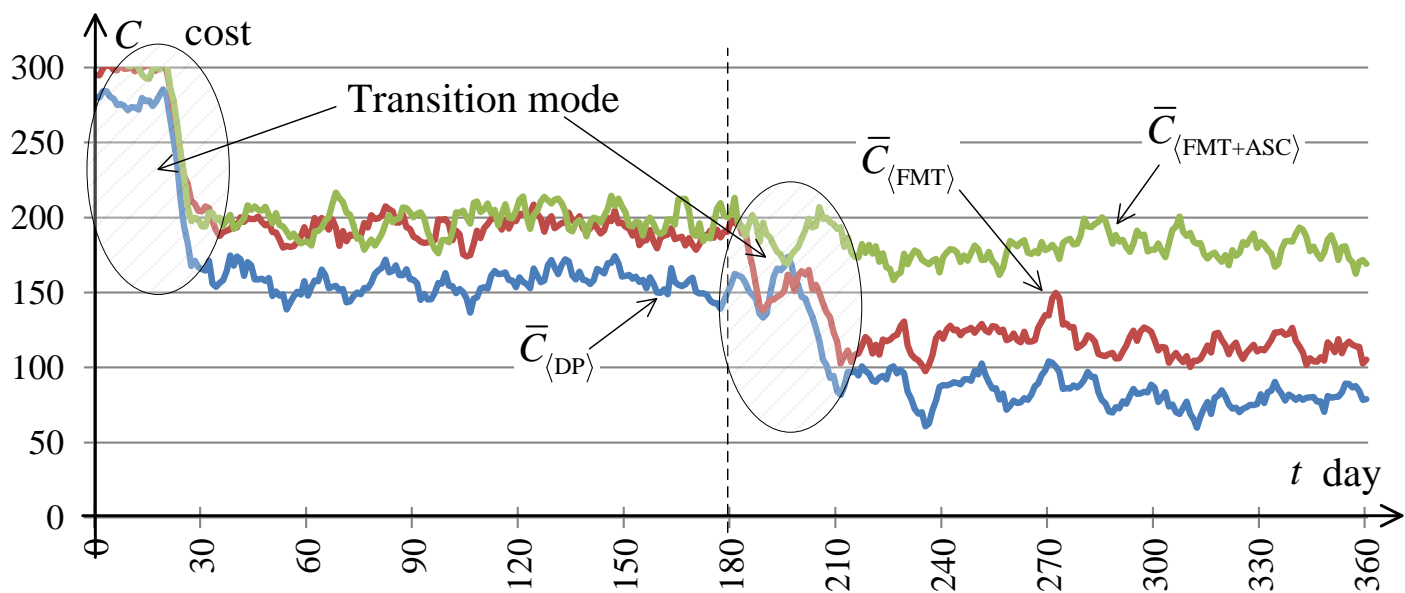

Figure 4. Average values of criteria functions for algorithms in the modernization of reconfigurable infocommunication environments.

Figure 5a estimated values of criteria functions for the compared control mechanisms. Figure $5 \mathrm{~b}$ shows the change in the ratio of performance of the mechanisms $\eta$ with ratio to the instantaneous values of the criterion function for the $\langle\mathrm{FMT}+\mathrm{ASC}\rangle$ mechanism: $\eta_{\langle\mathrm{FMT}\rangle}=\bar{C}_{\langle\mathrm{FMT}\rangle} / \bar{C}_{\langle\mathrm{FMT}+\mathrm{ASC}\rangle}$ and $\eta_{\langle\mathrm{DP}\rangle}=\bar{C}_{\langle\mathrm{DP}\rangle} / \bar{C}_{\langle\mathrm{FMT}+\mathrm{ASC}\rangle}$. 

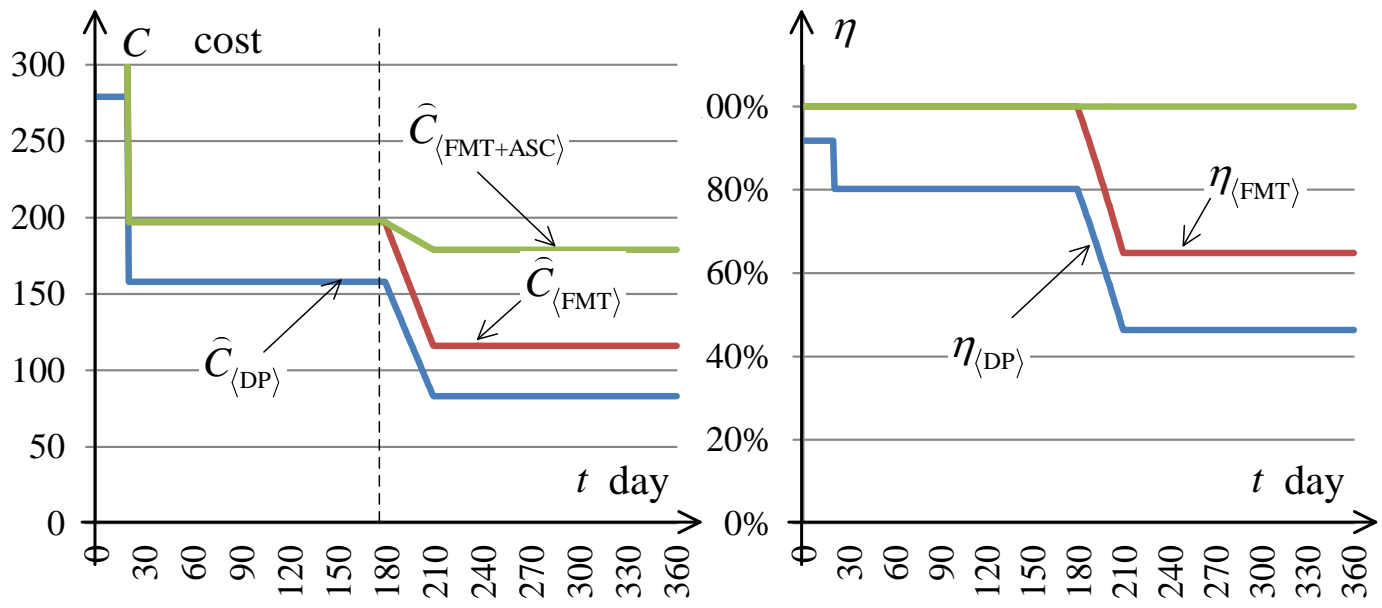

Figure 5. Absolute (a) and normalized (b) values of cost functions for compared algorithms.

The result of the experiment shows that a change in the structure of the IT request resource flow leads to a change in the efficiency of various application for compared algorithms. $<\mathrm{FMT}+\mathrm{ASC}>$ mechanism introduce control action $u_{R}^{V}(t=180)$, that change resource flow for required characteristics. Generated control changes the source characteristics and allows to plan reconfiguration more effectively. It justifies the need to manage resources in order to improve the development of the infocommunication environment under uncertainty due to adaptation of the IT components' requests flow structure. The amount of positive effect depends on variety (nonstationarity) of IT request resource flow intensity and structure.

Figures 6 and 7 show the main characteristics of IT requests service in reconfigurable infocommunication environment. Figure $6 \mathrm{a}$ shows absolute $\lambda_{\text {ITreq }}^{+}$and Figure $6 \mathrm{~b}$ shows normalized $\eta_{\text {ITreq }}^{+}$flow intensity of created IT components (new or modernized). Figure 7a shows absolute $\mu_{\text {ITreq }}^{-}$and Figure $7 \mathrm{~b}$ shows normalized values $\eta_{\text {ITreq }}^{-}=\mu_{\text {ITreq }}^{-} / \mu_{\text {ITreq },<\mathrm{FMT}+\mathrm{ASC}>}^{-}$of flow intensity of rejected IT requests:

$$
\mu_{\text {ITreq }}^{-}=\lambda_{\text {ITreq }}^{-} / \lambda_{\text {ITreq }} .
$$




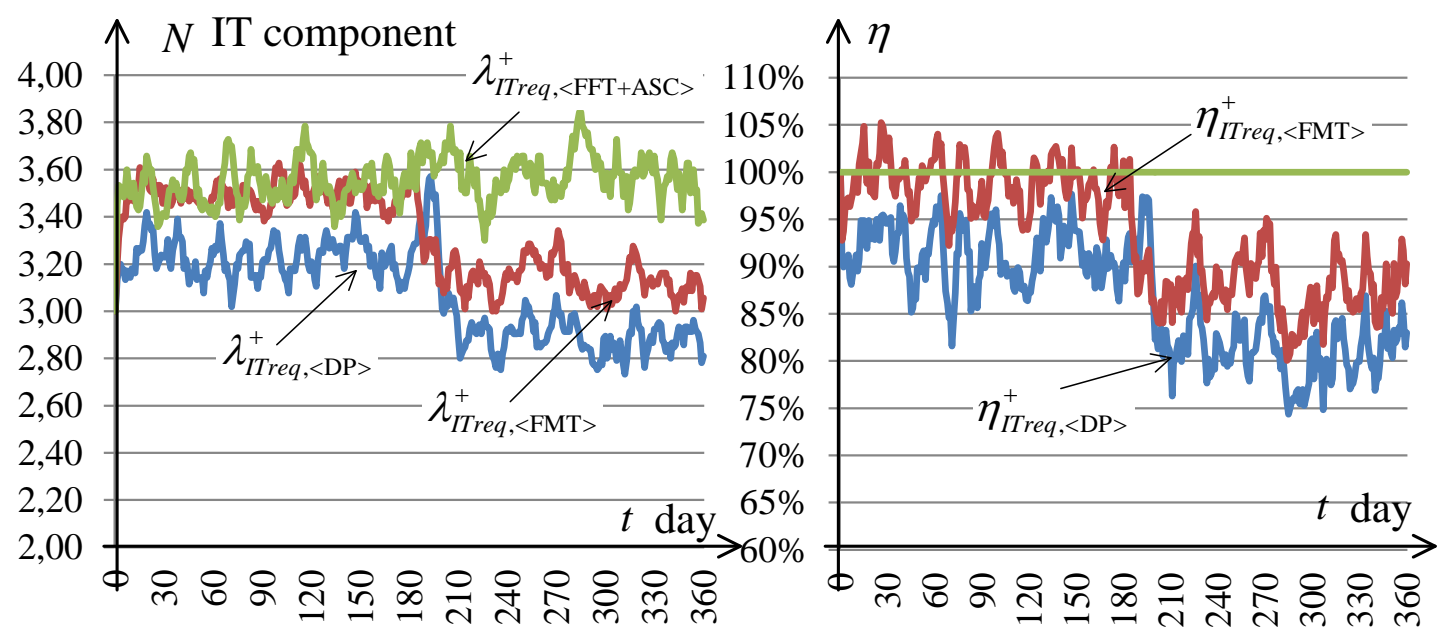

Figure 6. Absolute (a) and normalized (b) values of flow intensity of created IT components for compared algorithms.
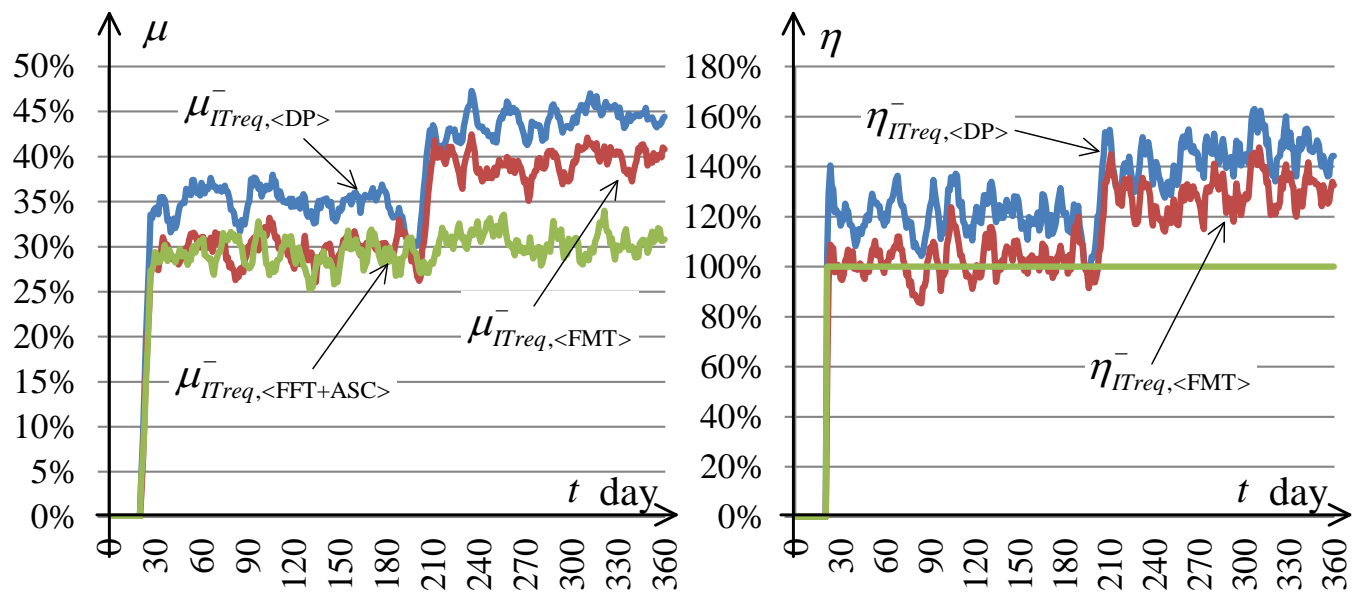

Figure 7. Absolutely (a) and normalized (b) values of share of flow intensity of rejected IT requests for compared algorithms.

\section{CONCLUSION}

The problem of multiple source-control for functional-structure modernization of reconfigurable infocommunication environments under uncertainty is investigated in the article. The uncertainty of resources flow characteristics forces to use special methods of resource allocation. The goal of article is to develop a new method of multiple sources resource control during the system's modernization. The proposed algorithm allows evaluating the quality of modernization sequences and organizing 
plans and source control according to the potential effect and characteristics of sources. The main features of the algorithm are: sources flow monitoring and modernized first - most timeliness (FMT) method for alternative selection, as well as resource flow control. To estimate the effect of the plans alternatives, the proposed cost function has been used. The experiments show that for non-stationary flow from multiple sources with different characteristics, the proposed method is more effective than alternatives. The direction of further research is to assess the impact of non-stationarity on the mechanisms of control and management of resources.

\section{ACKNOWLEDGEMENTS}

This work was prepared as a part of the state task FZWG -2020-0029 "Development of theoretical foundations for building information and analytical support for telecommunication systems for geo-ecological monitoring of natural resources in agriculture".

\section{REFERENCES}

[1] Sokolov B. V., Zaychik E. M., Ikonnikova A.V., Shaken S. A. Complex planning of modernization of information systems: methodological and methodical bases // Proceedings of spiiran. 2006. Vol.1. No. 3. P. 265-278.

[2] Myshenkov K. S., Belyashov A. N. Methodologies, methods and models for analysis and design of control systems. Vestnik MGTU Stankin. 2013. № 3 (26). P. 76-82.

[3] Kuzichkin, O.R., Eremenko, V.T., Loginov, I.V., Grecheneva, A.V., Vasilyev, G.S. Approach to the choice of modernization directions for the system of geodynamic monitoring in cases of using components intensity uncertainty // Indonesian Journal of Electrical Engineering and Computer Science. Vol 17. No 3: March 2020. Pp. 1239-1248.

[4] System analysis and decision-making: dictionary-reference: Studies. the allowance for high schools / Under the editorship of V. N. Volkova, V. N. Kozlov. - M.: Higher. SHK., 2004. - 616 p.

[5] Tahriri F., Osman M.R., Ali A., Yusuff R.M. A review of Supplier Selection Methods in Manufacturing Industries // Suranaree J. Sci. Technol. Vol. 15; No. 3; July - September 2008. Pp. 201-208.

[6] Kuzichkin, O.R., Loginov, I.V., Eremenko, V.T., Vasilyev, G.S., Grecheneva, A.V. Uncertainty of the implementation time of geodynamic monitoring system in multi-criteria ranking of alternatives // Indonesian Journal of Electrical Engineering and Computer Science. Vol 17. No 3: March 2020. Pp. 1249-1257. 
[7] Lin Ya-Ti, Lin Chia-Li, Yu Hsiao-Cheng, Tzeng Gwo-Hshiung. A Novel Hybrid MCDM Approach for Outsourcing Vendor Selection: A Case Study for a Semiconductor company in Taiwan // Expert System with Applications. Volume 37, Issue 7, July 2010, Pp. 4796-4804.

[8] Sheng-Li Si,1Xiao-Yue You,1,2Hu-Chen Liu,3and Ping Zhang DEMATEL Technique: A Systematic Review of the State-of-the-Art Literature on Methodologies and Applications // Mathematical Problems in EngineeringVolume 2018, Article ID 3696457, 33 pageshttps://doi.org/10.1155/2018/3696457.

[9] R. Rajesh and V. Ravi, "Modeling enablers of supply chainrisk mitigation in electronic supply chains: a Grey-DEMATELapproach,"Computers \& Industrial Engineering,vol.87,pp.126-139, 2015.

[10] Leschinsky B.S., Konkina Yu.A. Choice of supplier in conditions of data variability using methods of fuzzy set theory//Bulletin of Tomsk State University. Economy. 2008. № 2. C. 44-51.

[11] Koul S., Verma R. Dynamic Vendor Selection based on Fuzzy AHP Approach // Journal of Manufacturing Technology Management, Volume 22 (8): 9. Emerald Publishing - Oct 25, 2011. Pp. 963-971.

[12] Shyur H-J., Shih H-S. A Hybrid MCDM model for Strategic vendor selection // Mathematical and Computer Modelling. 2006. No. 44. P. 749-761.

[13] Chaudhry S.S., Lei Z., He Sh. Vendor Selection Problem: New Formulation and Solution Approach // IADS International Conference Applied Computing. 2006. Pp. 437-441.

[14] Sensoy M., Yolum P. A Context-Aware Approach For Service Selection Using Ontologies // AAMAS. 2006. May, 8-12. Hakodate, Hokkaido, Japan. Pp. 931931.

[15] Duran J.J., Iglesias C.A. A Pattern Approach to Modeling the Provider Selection Problem // ICAART 2010 - Proceedings of the International Conference on Agents and Artificial Intelligence, Volume 2 - Agents, Valencia, Spain, January 22-24, 2010. 8 p.

[16] Koul S., Verma R. Dynamic Vendor Selection based on Fuzzy AHP Approach // Journal of Manufacturing Technology Management, Volume 22 (8): 9. Emerald Publishing - Oct 25, 2011. Pp. 963-971.

[17] Tam C.Y. M., Tummala R/ V.M. An Application of the AHP in Vendor Selection of a Telecommunication System // Omega. No. 29. 2001. Pp. 171182.

[18] Weber Ch.A., Current J.R., Benton W.C. Vendor Selection Criteria and 
Methods // European Journal of Operational Research. No. 1991. Pp. 2-18.

[19] K. Sangaiah, P. R. Subramaniam, and X. Zheng, "A combined fuzzy DEMATEL and fuzzy TOPSIS approach for evaluating GSD project outcome factors, "Neural Computing and Applications, vol.26, no.5, pp.10251040,2015 .

[20] Cao Q., Leggio K. (2008) Applying the Real Option Approach to Vendor Selection in IT Outsourcing. In: Olson D.L., Wu D. (eds) New Frontiers in Enterprise Risk Management. Springer, Berlin, Heidelberg. https://doi.org/10.1007/978-3-540-78642-9_12.

[21] T. Lin, Y.-H. Yang, J.-S. Kang, and H.-C. Yu, "Using DEMA-TEL method to explore the core competences and causal effectof the IC design service company: an empirical case study,'Expert Systems with Applications,vol.38,no.5,pp.6262-6268,2011.

[22] Assellaou H., Ouhbi B., Frikh B. (2018) A Hybrid MCDM Approach for Supplier Selection with a Case Study. In: Amodeo L., Talbi EG., Yalaoui F. (eds) Recent Developments in Metaheuristics. Operations Research/Computer Science Interfaces Series, vol 62. Springer, Cham. https://doi.org/10.1007/9783-319-58253-5_12

[23] Dementiev D. N., Grishakov V. G., Loginov I. V. Algorithm of selection of perspective directions of modernization of control system of telecommunication network // Information systems and technologies. 2015. № 2 (88). P. 95-105

[24] Abdalov A.V., Grishakov V.G., Loginov I.V. Model of resource allocation of several sources during IT infrastructure reconfiguration//Information systems and technologies. 2019. №2 (112). C. 5-16.

[25] Petrovsky A. B. multi-criteria Group decision making with different preference // Scientific statement BSU. 152. № 15(70). 2009. p. 151-161. 
